\title{
latrogenic Complications in Five Patients with Upper Gastrointestinal Bleeding due to Ambient Air: Case Series and Literature Review
}

\section{Christine N. Manser Peter Bauerfeind Christoph Gubler}

Clinic of Gastroenterology and Hepatology, Department of Internal Medicine, University Hospital, Zurich, Switzerland

\section{Key Words}

Endoscopy · Ambient air · latrogenic complication

\begin{abstract}
Despite the increasing use of carbon dioxide for endoscopies during the last years, ambient air is still used. The amount of air depends on several factors such as examination time, presumable diameter of the endoscope channel and of course active use of air by the operator. Although endoscopic complications due to ambient air in the gastrointestinal (GI) tract are a rare observation and mostly described in the colon, we report five cases in the upper GI tract due to insufflating large amounts of air through the endoscopes. All 5 patients needed an emergency upper endoscopy for acute presumed upper GI bleeding. In two cases both esophageal variceal bleeding and ulcer bleeding were detected; the fifth case presented with a bleeding due to gastric cancer. Due to insufflation of inadequate amounts of air through the endoscope channel, all patients deteriorated in circulation and ventilation. Two rumenocenteses and consecutively three laparotomies had to be performed in three patients. In the other two, gastroscopies had to be stopped for an emergency computed tomography. All critical incidents were believed to be a consequence of a long-lasting examination with use of too much air. Therefore in emergency situations, endoscopies should be performed with either submersion, low air flow pumps or even better by the use of carbon dioxide.
\end{abstract}




\section{Introduction}

Distension of the hollow organs has been induced by ambient air since the introduction of endoscopes for gastrointestinal (GI) indications. The ambient air is delivered at the distal end of the endoscope with a fixed amount per minute by the operator's pushing of the air button. Standard gastroscopes and colonoscopes are of little difference with respect to the amount of delivered air. In the last years, carbon dioxide $\left(\mathrm{CO}_{2}\right)$ instead of ambient air has become the standard in colonoscopy and endoscopic examinations with longer operation times, such as double balloon enteroscopy or mucosectomies.

While insufflated air mainly leaves the patient's body per vias naturales, i.e. either the esophagus, small bowel or finally the colorectum, diffusion is not fast enough to clear these volumes to guarantee harmless endoscopic procedures. Ambient air consists mainly of nitrogen, which has a very slow diffusion capacity in human tissue, while the amount of $\mathrm{CO}_{2}$ is only about $0.03 \%$. Therefore the operator always has to keep in mind which amount of gas (air or $\mathrm{CO}_{2}$ ) will be delivered into the hollow organs. Important variables are examination time, ambient air versus $\mathrm{CO}_{2}$ insufflation, diameter of the endoscope channel, operator's fingers on the push button and setting of the air pump. Anyhow emergency gastroscopies seem to harbor an elevated risk for development of air-induced complications. Adequate ventilation may therefore not be possible anymore. Using water instead of air may be of help, but is dangerous as well in upper endoscopy without airway protection. Repetitive suction of air during the examination should be done as often as visibility allows.

Barotrauma in the GI tract occurs in scuba diving, GI endoscopy, noninvasive ventilation [1] or in blast injuries [2]; pertaining GI endoscopy in the colorectum is affected mostly. In this context a single-center case series has been published lately. $34.6 \%$ of 26 colonic perforations in 19,135 patients were attributed to barotrauma [3]. Upper GI perforation is very rarely caused by barotrauma and only rare information exists in the literature, apart from reports on barotrauma due to bag ventilation [4] or resuscitation [5]. Whether an acute upper GI bleeding influences gas transport along the small and large bowel, predisposing for a compartment syndrome, is not known to date. At our tertiary referral center, five situations with an iatrogenic compartment syndrome after upper GI endoscopy were documented in the last 2 years, always leading to a life-threatening situation. Alertness concerning the insufflation process in GI endoscopy will help prevent distension-associated diseases. From now on this entity has to be taught in endoscopy education. The following elaborated simple rules for emergency endoscopies should be implemented in daily routine.

\section{Case Reports}

Case 1

Esophageal variceal bleeding was suggested in a 37-year-old unconscious woman with overt bleeding from the mouth and anus, who was admitted to our emergency room with an initial hemoglobin of $2.7 \mathrm{~g} / \mathrm{dl}$ and an initial systolic blood pressure of $80 \mathrm{~mm} \mathrm{Hg}$. Liver cirrhosis had not been diagnosed before. Esophageal variceal bleeding was suggested due to the information that the patient had been drinking daily since early youth and that 2 weeks before admission to the emergency room, the patient had had to go to the family doctor because of becoming jaundiced. The Model for End-Stage Liver Disease (MELD) score [6] at admission was 15. Emergency endoscopy was performed 
directly using a large channel ( $6 \mathrm{~mm}$ diameter) endoscope. After $1 \mathrm{~h}$ of endoscopy, mechanical ventilation became impossible due to an abdominal compartment syndrome. Immediate laparotomy was performed and the stomach had to be evacuated from air and coagula manually with a simultaneously positioned 52-F tube. To stop the ongoing bleeding after coagula evacuation, a Sengstaken-Blakemore balloon was placed. During the first $24 \mathrm{~h}$ the patient received 16 erythrocyte concentrates, 2 platelet concentrates, $1,200 \mathrm{ml}$ fresh frozen plasma, $10 \mathrm{~g}$ fibrinogen and coagulation factors (2,000 IU Beriplex ${ }^{\circledR}$, see table 1, plus 1,250 IU coagulation factor XIII). Due to repetitive declines in hemoglobin and the endoscopic proof of bleeding from the esophagus, the patient got a transjugular intrahepatic portosystemic shunt (TIPSS) inadequately lowering the directly measured portal pressure from 46 to $35 \mathrm{~mm} \mathrm{Hg} 2$ days later. The patient's hepatic function, however, remained impaired, the reason why the patient was listed for transplantation on hospital day 5 (MELD score at that time was 29) and transplanted on hospital day 12. Today, 2.5 years later, the patient is in good health.

\section{Case 2}

A 56-year-old woman with non-steroidal anti-inflammatory drug (NSAID) (acemetacin 60-90 mg) intake due to chronic polyarthritis was referred to the emergency room with melena and circulatory instability. The initial hemoglobin value measured in the emergency room was $3.5 \mathrm{~g} / \mathrm{dl}$, the initial median arterial pressure was $50 \mathrm{~mm} \mathrm{Hg}$. A bleeding ulcer was suspected to be responsible due to the NSAID intake. After tracheal intubation, a gastroscopy was started using a $2.8 \mathrm{~mm}$ working channel endoscope parallel to an intravenous therapy with a proton pump inhibitor ( $80 \mathrm{mg}$ as bolus followed by $8 \mathrm{mg} / \mathrm{h}$ for the next $72 \mathrm{~h}$ ). As a large coagulum filling most of the stomach was detected, the endoscope was exchanged for the large channel endoscope ( $6 \mathrm{~mm}$ diameter). Shortly thereafter, ventilatory problems occurred and a CT scan was immediately arranged presenting extensive meteorism without evidence of perforation. A second endoscopy was done after exclusion of perforation showing an ulcer with a visible vessel (Forrest IIa, fig. 1) necessitating the application of two metal clips. Except for meteorism the patient did not suffer from additional symptoms during the following days and was discharged 6 days later.

Case 3

Initially the 83-year-old patient had been transferred to a peripheral hospital, but due to hemodynamic instability he was transferred to our center. He had been diagnosed with carcinoma of the stomach 1 week before and presented with acute onset of hematemesis and a decline of the hemoglobin value from 9.5 to $6.7 \mathrm{~g} / \mathrm{dl}$ within a week. After arrival at our center the hemoglobin had risen to $8.9 \mathrm{~g} / \mathrm{dl}$ due to the application of two erythrocyte concentrates. After tracheal intubation a gastroscopy was started. Due to large amounts of blood it was switched to the large channel endoscope ( $6 \mathrm{~mm}$ diameter). After $5 \mathrm{~min}$ the patient developed massive abdominal distension with increasing difficulties of mechanical ventilation. A perforation was presumed. CT scan showed massive distension of the stomach and small bowel without perforation (fig. 2). Repeated endoscopy showed an ongoing bleeding near the cardia which could not be stopped; besides the patient developed an abdominal compartment syndrome with a bladder pressure of $37 \mathrm{~mm} \mathrm{Hg}$. Therefore an emergency laparotomy was performed. At that point the patient required $50-60 \mu \mathrm{g} / \mathrm{kg} / \mathrm{min}$ of norepinephrine. The tumor affected not only the stomach but had also infiltrated the pancreas and colon as well as eroded the splenic artery. Due to the only marginal survival chance in case of an extensive surgery and a controlled bleeding at that time, the operation was finished after exploration. Postoperatively the patient remained circulatorily and hemostatically instable, leading to death within hours.

Case 4

A 78-year-old patient, who was hospitalized due to tachycardic atrial fibrillation and aortocoronary bypass surgery, developed upper GI bleeding on hospital day 9. Two large duodenal ulcers were diagnosed (fig. $3 \mathrm{a}$ ). Despite ulcer treatment with endoclips as well as proton pump inhibitor therapy, the patient again developed a bleeding leading to another upper endoscopy 6 days after the first endoscopy. Despite revealing an in situ present clip on one of the duodenal ulcers, the endoscopy showed large amounts of blood and coagula in the duodenum (fig. 3b, c). The site of bleeding, however, could not be located. Within a few minutes, increasing difficulties in the patient's mechanical ventilation occurred, and increasing norepinephrine requirement from 10 to $50 \mu \mathrm{g} / \mathrm{kg} / \mathrm{min}$ made an emergency treatment by rumenocentesis necessary. The immediately performed emergency surgery revealed a massive distension with several serosal disruptions of stomach, small intestine and colon. A resection of the antrum and pars I duodeni with Billroth II 
reconstruction had to be done due to perforation into the omentum majus. Three days later a hemicolectomy was necessary due to persisting colon distension and serosal disruptions. Due to chronic renal insufficiency recovery was delayed and the patient was dismissed 2 months later.

Case 5

A 48-year-old patient with hemorrhage from esophageal varices was transferred to our center for a TIPSS due to persisting bleeding. In the external hospital two upper endoscopies with endoscopic variceal ligation as well as inlay of a Linton-Nachlas and consecutively a Sengstaken-Blakemore balloon catheter had been conducted. Besides the patient had been given 8 erythrocyte concentrates, 3 thrombocyte concentrates, $600 \mathrm{ml}$ of fresh frozen plasma as well as coagulation factors $(3,600 \mathrm{IU}$ Prothromplex $^{\circledast}$, see table 1). Soon after arrival at our center the patient developed an abdominal compartment syndrome with quickly increasing difficulties in ventilation and elevated bladder pressure $>20 \mathrm{~mm} \mathrm{Hg}$. As a rumenocentesis did not resolve the problem, the patient required an emergent laparotomy. Due to worsening liver function with a MELD score of 23 and elevated bilirubin $(102 \mu \mathrm{mol} / \mathrm{l})$, TIPSS implantation was judged to be contraindicated. The patient needed three surgical revisions, and a repeated gastroscopy showed large esophageal varices, which were treated with rubber band ligation 7 days after admission (fig. 4 ). The patient did not recover from abdominal surgery. One week after the compartment syndrome, liver function deteriorated progressively, reaching a maximum MELD of 40 probably as the consequence of surgery. A liver transplantation was discussed and rejected; we lost the patient due to multi-organ failure.

Patient characteristics are summarized in table 2. Notably all endoscopies were performed in an emergency room, using ambient air for stomach distension. All patients were circulatorily compromised with hypotension and needed tracheal intubation for mechanical ventilation and airway protection. Etiology was always an ongoing upper GI bleeding. The therapeutic approach was on the other hand different. Three patients ended up with a laparotomy after unsuccessful rumenocentesis in two. The indication for an operative procedure was based on clinical judgment. These three patients experienced a probably more severe GI bleeding. The other two underwent a CT scan. After exclusion of a free perforation and cessation of the endoscopy, the clinical course was benign, allowing a repetition of the endoscopy. Mortality was $40 \%$ (2/5 patients) within 30 days, although only in one case (No. 5) causality with the barotraumas was obvious.

\section{Discussion}

Upper GI bleeding is always a challenging examination for the endoscopist, as affected patients are often instable concerning circulation and need a tracheal intubation before any intervention. The lumen of the stomach is mostly inadequately prepared for a proper inspection or even therapeutic intervention. Preparation, however, might be optimized by erythromycin applied intravenously before endoscopy [7], which should therefore be recommended routinely.

In all the above reported endoscopies the distension of the stomach, small bowel and even colon generated life-threatening conditions mainly associated with rapidly progressive difficulty to oxygenate the patient. In all cases the emergent endoscopy with different instruments induced an unpredictable amount of air in the GI tract within few minutes examination time, leading to interruption of the procedures, additional examinations like CT scans and even laparotomy. Diagnostic procedures such as CT scan or laparotomy may be avoided by strict suction of the air leaving the endoscope within the stomach. If patients are instable without sufficient oxygenation and the air has already been distributed all over the GI tract, this strategy may not be an option anymore. CT scans are of little help in the setting of rapid ballooning of the abdomen because suspected perforation would rather produce peritonism than impressive ballooning. Distended bowel loops may be distinguished from evolving peritonitis following perforation purely by clinical examination. 
Upper GI endoscopy leading finally to an abdominal compartment syndrome requiring surgery is extremely rare and has, to our knowledge, not been reported to date. In the colon barotrauma, as already mentioned, is rare but well known. Duration of the examination, air trapping due to stenosis in the sigmoid [8] or even argon plasma coagulation therapy leading to an explosion [9] are known causes. $\mathrm{CO}_{2}$ will therefore become standard nowadays; it is easily available and cheap, and the additional infrastructure is minimal and can be mounted of all types of light sources.

In conclusion, we recommend the intravenous application of erythromycin 20$30 \mathrm{~min}$ in advance of endoscopy to increase visibility and thus reduce endoscopy time. Nevertheless large channel endoscopes have to be used with caution and knowledge about the insufflation power. The air pump should be switched to the lowest possible level. $\mathrm{CO}_{2}$ insufflation instead of ambient air is wishful and in case of intubated patients, water instead of air should be used as often as possible. In longer-lasting endoscopies the endoscopist should repetitively palpate the patient's abdomen to anticipate an abdominal compartment syndrome. Any endoscopist training has to point out the dos and don'ts of an emergency examination.

Table 1. Formulations of supplied coagulation factor mixtures

\begin{tabular}{lllc}
\hline Beriplex ${ }^{\circledR}$ P/N 500 & Content (IU)/500 & Prothromplex ${ }^{\circledR}$ NF 600 & Content (IU)/600 \\
\hline Coagulation factor II & $400-960$ & Coagulation factor II & 600 \\
Coagulation factor VII & $200-500$ & Coagulation factor VII & 500 \\
Coagulation factor IX & $400-600$ & Coagulation factor IX & 600 \\
Coagulation factor X & $440-1,200$ & Coagulation factor X & 600 \\
Protein C & $300-900$ & Protein C & $\geq 400$ \\
Protein S & $240-760$ & Antithrombin & $15-30$ \\
Antithrombin & $4-30$ & Heparin & $\leq 0.5 /$ IU factor IX \\
Heparin & $8-40$ & & \\
\hline
\end{tabular}

Table 2. Patient characteristics

\begin{tabular}{llllll}
\hline & Patient 1 & Patient 2 & Patient 3 & Patient 4 & Patient 5 \\
\hline Gender & female & female & male & male & male \\
Age, years & 37 & 56 & 83 & 78 c & 48 \\
Duration of endoscopy & $>1 \mathrm{~h}$ & $>1 \mathrm{~h}$ & $>1 \mathrm{~h}$ & $<1 \mathrm{~h}$ & $>1 \mathrm{~h}$ \\
Etiology of GI bleeding & esophageal varices & stomach ulcer & gastric cancer & duodenal ulcers & esophageal varices \\
Intubation & + & + & + & + & + \\
Laparotomy & + & - & + & - & + \\
CT scan & - & + & + & + & + \\
Rumenocentesis & - & - & - & + & - \\
30-day survival & + & + & - & + \\
\hline
\end{tabular}




\begin{tabular}{r|l|l|l}
$\begin{array}{r}\text { Case Reports in } \\
\text { Gastroenterology }\end{array}$ & $\begin{array}{l}\text { Case Rep Gastroenterol 2012;6:197-204 } \\
\text { DOI: 10.1159/000338647 }\end{array}$ & $\begin{array}{l}\text { Published online: } \\
\text { April 25, 2012 }\end{array}$ & $\begin{array}{l}\text { O 2012 S. Karger AG, Basel } \\
\text { ISSN 1662-0631 } \\
\text { www.karger.com/crg }\end{array}$ \\
\hline
\end{tabular}

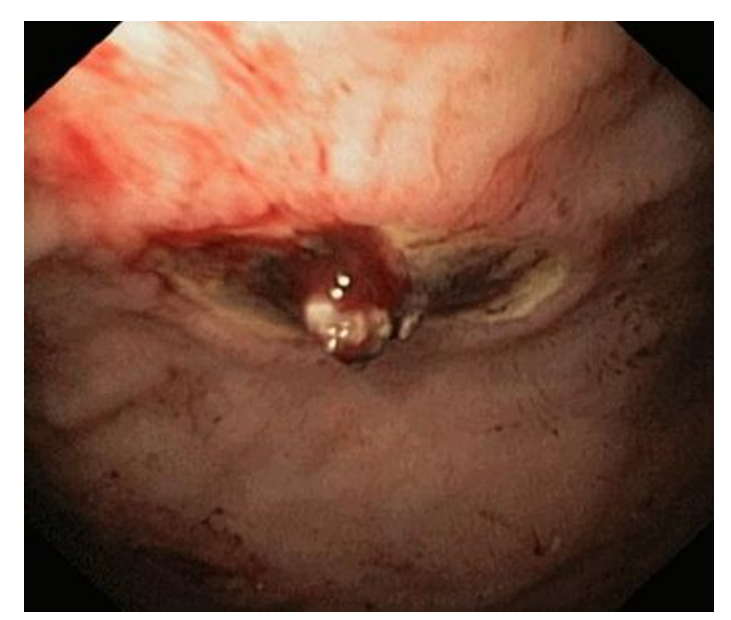

Fig. 1. The endoscopic image of patient 3 shows an ulcer in the stomach with visible vessel.

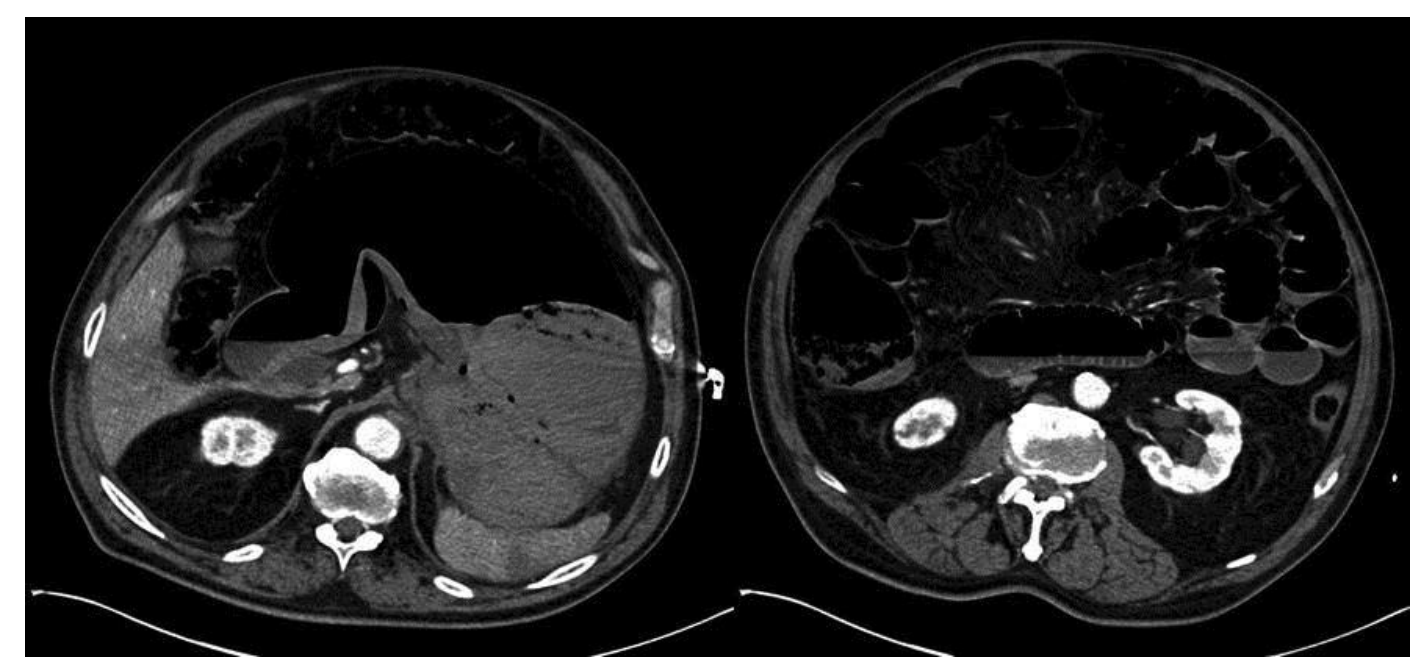

Fig. 2. CT scan of patient 2 shows distension of the stomach and small bowel (immediately after endoscopy). 


\begin{tabular}{r|l|l|l}
$\begin{array}{r}\text { Case Reports in } \\
\text { Gastroenterology }\end{array}$ & $\begin{array}{l}\text { Case Rep Gastroenterol 2012;6:197-204 } \\
\text { DOl: 10.1159/000338647 }\end{array}$ & $\begin{array}{l}\text { Published online: } \\
\text { April 25, 2012 }\end{array}$ & $\begin{array}{l}\text { @ 2012 S. Karger AG, Basel } \\
\text { ISSN 1662-0631 } \\
\text { www.karger.com/crg }\end{array}$ \\
\hline
\end{tabular}
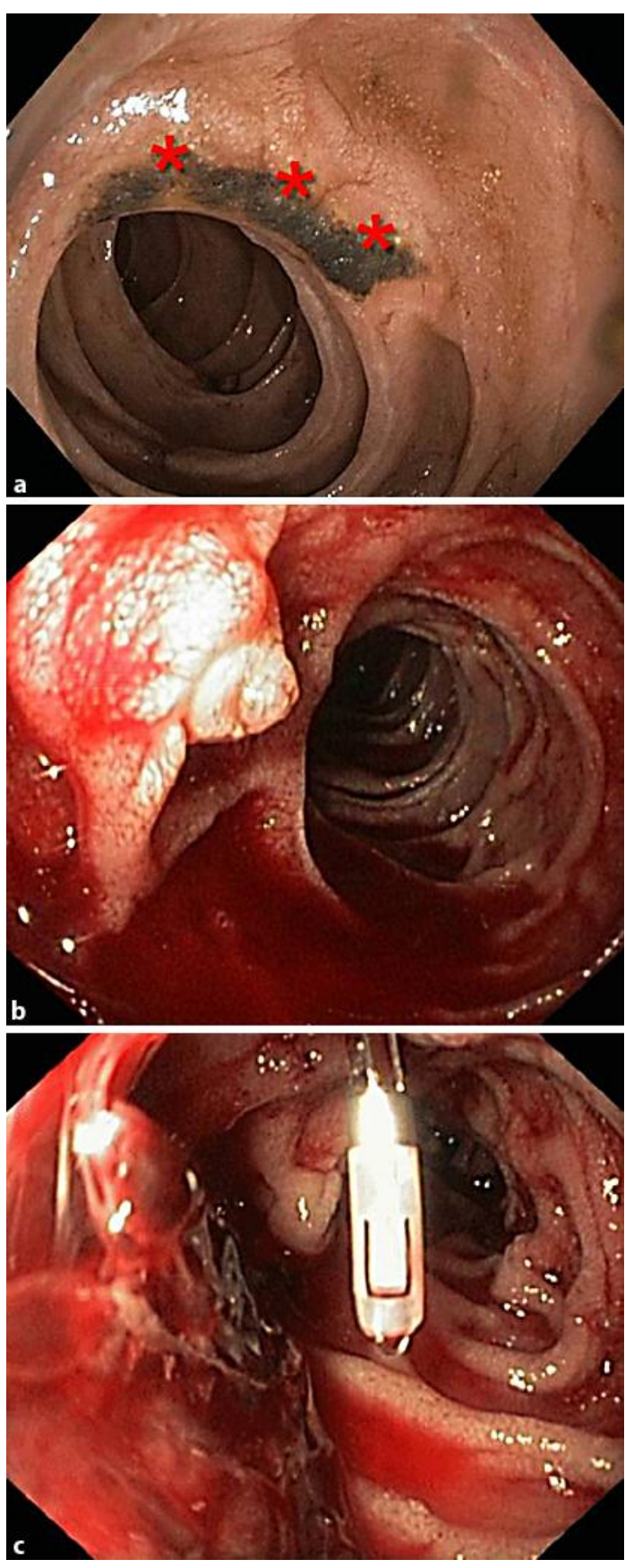

Fig. 3. Endoscopic images of patient 4 show: a A large duodenal ulcer with hematin (asterisks) in the first endoscopy. b Major papilla with larger amounts of blood in the second endoscopy. c Clip in situ on one of the ulcers, coagula in the second endoscopy. 


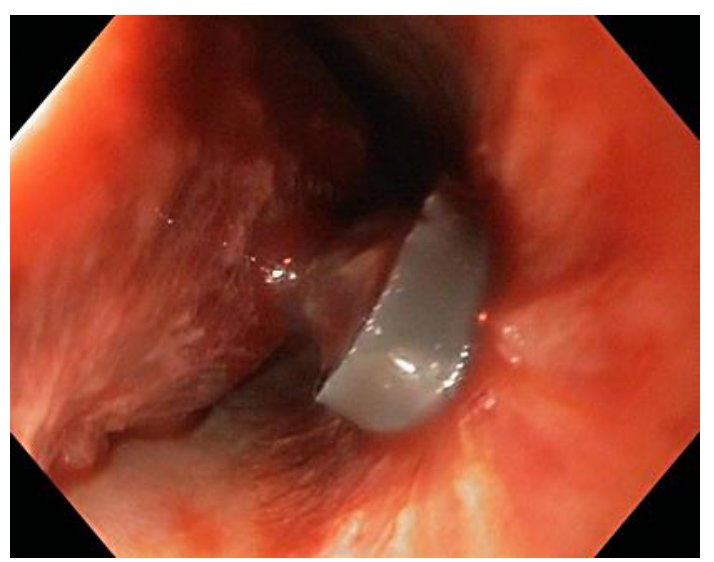

Fig. 4. The endoscopic finding in patient 5 shows a rubber band and a necrotic varix.

\section{References}

1 Jean-Lavaleur M, Perrier V, Roze H, et al: Stomach rupture associated with noninvasive ventilation (in French). Ann Fr Anesth Reanim 2009;28:588-591.

$>2$ Wolf SJ, Bebarta VS, Bonnett CJ, Pons PT, Cantrill SV: Blast injuries. Lancet 2009;374:405-415.

3 Loffeld RJ, Engel A, Dekkers PE: Incidence and causes of colonoscopic perforations: a single-center case series. Endoscopy 2011;43:240-242.

4 Malik SM, Rockacy M, Al-Khafaji A: Bleeding after bagging. Diagnosis: Gastric rupture and massive pneumoperitoneum secondary to barotrauma from bag ventilation. Gastroenterology 2011;141: e16-e17.

5 Smally AJ, Ross MJ, Huot CP: Gastric rupture following bag-valve-mask ventilation. J Emerg Med 2002;22:27-29.

6 Kamath PS, Wiesner RH, Malinchoc M, et al: A model to predict survival in patients with end-stage liver disease. Hepatology 2001;33:464-470.

7 Frossard JL, Spahr L, Queneau PE, et al: Erythromycin intravenous bolus infusion in acute upper gastrointestinal bleeding: a randomized, controlled, double-blind trial. Gastroenterology 2002;123: 17-23.

8 Sanchez-Munoz D, Ortiz-Moyano C, Ramirez-Martin del Campo M, et al: Pneumatic perforation of the cecum during diagnostic sigmoidoscopy. Endoscopy 2007;39(suppl 1):E183.

9 Manner H, Plum N, Pech 0, Ell C, Enderle MD: Colon explosion during argon plasma coagulation. Gastrointest Endosc 2008;67:1123-1127. 